\title{
Gender inequality: Bad for men's health
}

\author{
M Cornell
}

Centre for Infectious Disease Epidemiology and Research, School of Public Health and Family Medicine, Faculty of Health Sciences, University of Cape Town

M Cornell, MPH (Epidemiology)

Corresponding author: M Cornell (morna.cornell@uct.ac.za)

Men's increased risk of death in ART programmes in sub-Saharan Africa is widely reported but poorly understood. Some studies have attributed this risk to men's poorer health-seeking behaviour, which may prevent them from accessing ART, being adherent to treatment, or remaining in care. In a multicentre analysis of 46201 adults starting ART in urban and rural settings in South Africa, these factors only partly explained men's increased mortality while receiving ART. Importantly, the gender difference in mortality among patients receiving ART (31\% higher for men than women) was substantially smaller than that among HIVnegative South Africans, where men had twice the risk of death compared with women. Yet, this extreme gender inequality in mortality, both within and outside of ART programmes, has not given rise to widespread action. Here it is argued that, despite their dominance in society, men may be subject to a wide range of unfair discriminatory practices, which negatively affect their health outcomes. The health needs of men and boys require urgent attention.

S Afr J HIV Med 2013;14(1):12-14. DOI:10.7196/SAJHIVMED.894

Sub-Saharan Africa is the centre of the HIV epidemic, with an estimated $68 \%$ of all people HIV-infected. ${ }^{\text {(1) }}$ Over the past 10 years, largely through international aid programmes, there has been a dramatic increase in the number of HIV-infected individuals who have started antiretroviral therapy (ART) in the region. Despite early concerns that women may be disadvantaged in ART programmes, disproportionately more women than men have accessed ART in Southern Africa. ${ }^{[2]}$ In South Africa, for example, $60 \%$ of eligible women were receiving ART by mid-2011 compared with $41 \%$ of eligible men. ${ }^{[3]}$

Men have a higher mortality than women when receiving ART ${ }^{[4.8]}$ Although the reasons for this are poorly understood, a number of possible explanations have been suggested; some implicitly blame men for their own poorer outcomes. For example, numerous studies have suggested that men's poorer 'health-seeking behaviour' may prevent them from accessing ART services, being adherent to treatment or remaining in care. But, is this based on evidence or is it an assumption that has gained currency through widespread usage?

To date, there has been no systematic attempt to understand the phenomenon of gender differences on ART. In the past year, we explored the issue in an analysis including 46201 adults initiating ART in 8 large urban and rural South African cohorts between 2002 and 2009. ${ }^{[5]}$ As $60 \%$ of our patients had civil identification (ID) numbers, it was possible to confirm their vital status through linkage to the National Population Register, estimated to capture over $90 \%$ of deaths nationally. ${ }^{[9]}$ We were also able to track patients with IDs after they were lost to follow-up (LTF) and confirm whether they were alive or dead.

\section{Men's increased mortality on ART unrelated to HIV/AIDS}

At the start of treatment, on average men had lower CD4+ cell counts and more advanced HIV disease than women. After we adjusted for such gender differences at ART initiation, men still had a $31 \%$ higher risk of mortality than women over 36 months (adjusted hazard ratio (AHR) 1.31, 95\% confidence interval (CI) 1.22 - 1.41). Men were more likely to be LTF than women (AHR $1.20,95 \%$ CI 1.12 - 1.28), but not to die after being LTF (AHR $1.04,95 \%$ CI 0.86 - 1.25). Virological responses to ART were similar between men and women and, even among virologically suppressed patients, men were still more likely to die. Women had slightly stronger immunological responses than men, but in analyses restricted to patients who had reached CD4+ cell counts $\geq 200$ cells $/ \mu \mathrm{l}$, the gender difference in mortality persisted (AHR 1.37, 95\% CI 1.03 - 1.83). Importantly, however, this difference was smaller than the gender difference in death rates (standardised by age) in a hypothetical cohort of HIVnegative South Africans, where men were twice as likely to die than women. It appears then that the observed differences in mortality while receiving ART may best be explained by background gender differences in mortality in the South African population that are unrelated to HIV/AIDS.

\section{Some more equal than others?}

The gender differences in mortality outside of ART programmes suggest a situation of extreme gender inequality. The World Health Organization (WHO) defines gender inequality as 'difference(s) between men and women which systematically 


\section{Table 1. Conceptualising discrimination as a determinant of population health}

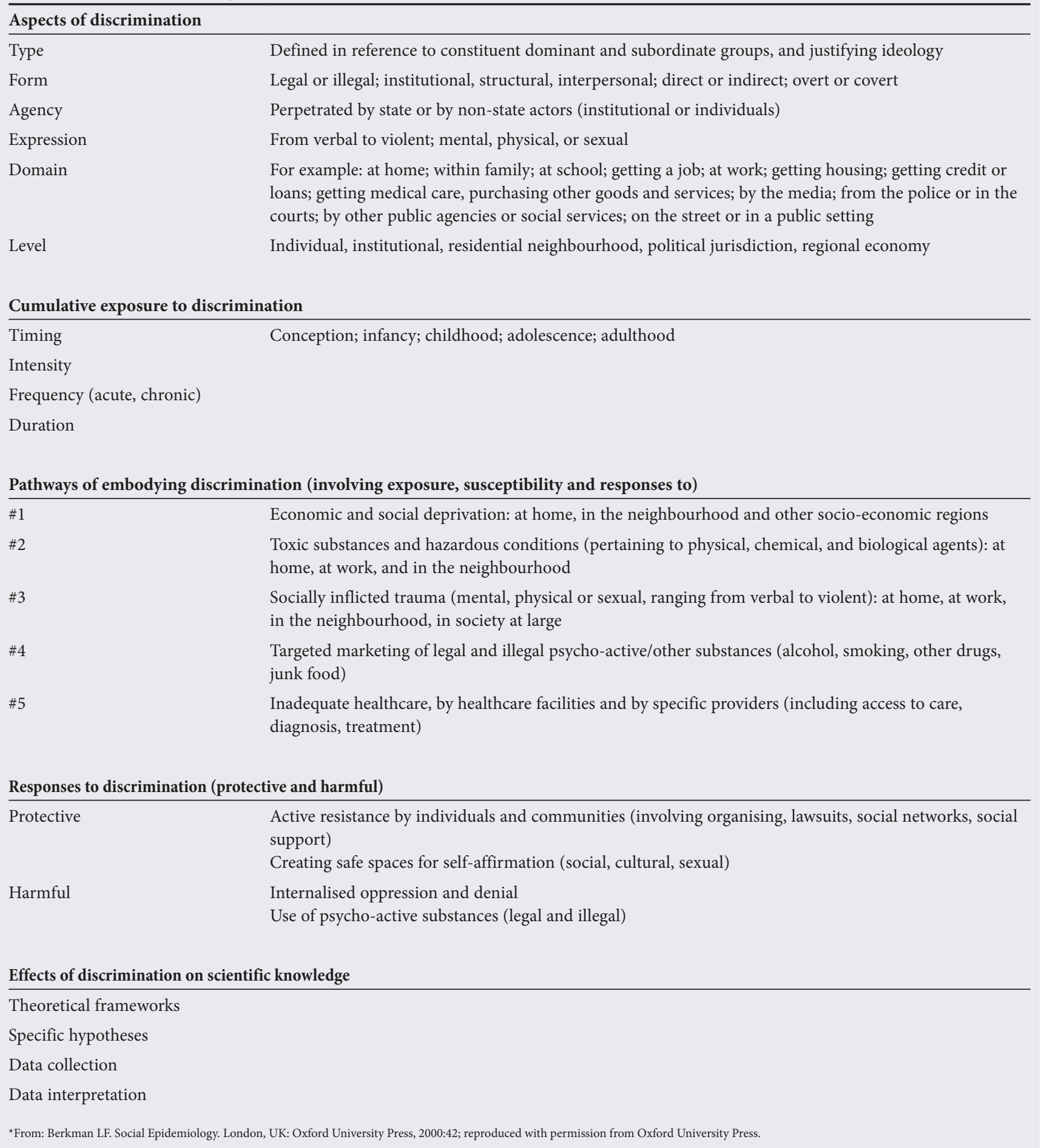

empower one group to the detriment of the other' and which impact negatively on access to healthcare and health status. ${ }^{[10]}$ Section 9 of the South African Bill of Rights states unequivocally that 'everyone is equal before the law. ${ }^{\text {[11] }}$ Equality includes protection against unfair discrimination (both direct and indirect) on the grounds of gender, and discrimination on any of the grounds mentioned is regarded as unfair unless proven to be fair. But, for many of us, discrimination seems a vague and unmeasurable concept. We have an intuitive sense of what it means, but how do we study it in order to address it? Krieger provides a useful framework to conceptualise how unfair discrimination affects population health (Table 1). On this basis it appears that, despite their dominance in society, men may be subject to a wide range of unfair discriminatory practices over their entire lives, through multiple pathways, with generally harmful responses.

There are few studies exploring the issue of discrimination towards men in health services. In contrast, there is a large body of literature 
on discrimination and women's health, ${ }^{[12-21]}$ possibly in response to the historic under-representation of women in research informing medical practice. In 1993 the United States National Institutes of Health (NIH) was mandated by law to ensure that 'women and minority groups' were included in clinical research. ${ }^{[22]}$ While this was a welcome response to an important omission from international research agendas, is it possible that the pendulum has swung too far? It seems probable that we are unable to recognise gender inequality when it affects men.

The priorities and programmes of large funders appear to confirm the focus on women in HIV/AIDS programmes. For example, the Global Fund for HIV/AIDS, Tuberculosis and Malaria - the largest multilateral HIV/AIDS funding agency - states that equitable access to services is fundamental to its mission but does not include men's poorer access to ART as a key action area. The United States of America, the largest donor on HIV/AIDS, has provided funding for nearly 2.5 million people living with HIV through its President's Emergency Plan for AIDS Relief (PEPFAR) programme. Although disproportionately more women than men have accessed ART, PEPFAR does not prioritise increasing men's access to treatment.

In turn, funders' priorities may affect national ART programmes. In Zambia, $54 \%$ of those living with HIV, but $63 \%$ of adults starting ART, are women. ${ }^{[23]}$ In South Africa, too, there is a gender gap: 55\% of those living with HIV, but only an estimated $68 \%$ of those starting public sector ART, are women. ${ }^{[2]}$ Yet, the national strategic plans for HIV/ AIDS in both countries do not identify male access to ART as a priority, nor do they include action plans to address this gap urgently. The same is true for many other African countries.

This apparent lack of concern for men's needs extends beyond ART programmes to other arenas. Policy documents define gender as the 'socially constructed roles, behaviours, activities and attributes' considered appropriate for men and women in particular settings. ${ }^{[10]}$ In practice, however, it seems that gender and women's issues are still regarded as interchangeable. For instance, South Africa has a ministry for women, children and people with disabilities, but nothing comparable for men. Similarly, the United Nations has an Inter-Agency Network on Women and Gender Equality and the third Millennium Development Goal for 2015 is to 'promote gender equality and empower women'. The UNAIDS's Operational Plan on gender addresses 'women, girls, gender equality and HIV', but none of the three action areas refers to the needs of men or boys. Clearly the initiatives listed above are vital, as are initiatives to address the health needs of men. In the words of WHO: 'no one should be sick or die because of gender inequality'

One last point for readers to consider: Many international and national conferences, including the recent conference of the Southern African HIV Clinicians Society, include tracks on women's health, but not that of men. Is this because there are no HIV-related issues specific to men's health - or is it because the question was not asked?

\section{References}

1. United Nations Programme on HIV/AIDS. How to get to zero: Faster. Smarter. Better. UNAIDS World AIDS Day Report. Geneva, Switzerland: UNAIDS, 2011.

2. Muula A, Ngulube T, Siziya S, et al. Gender distribution of adult patients on highly active antiretroviral therapy (HAART) in Southern Africa: A systematic review. BMC Public Health 2007;7(1):63.

3. Johnson L. Access to antiretroviral treatment in South Africa, 2004 - 2011. Southern African Journal of HIV Medicine 2012;13(1):22-27.

4. Auld AF, Mbofana F, Shiraishi RW, Sanchez M, Alfredo C, Nelson LJ, et al. Fouryear treatment outcomes of adult patients enrolled in mozambique's rapidly expanding antiretroviral therapy program. PLoS One 2011;6(4):e18453. [http:// dx.doi.org/10.1371/journal.pone.0018453]

5. Cornell M, Schomaker M, Garone DB, et al. Gender differences in survival among adult patients starting antiretroviral therapy in south africa: A multicentre cohort study. PLoS Med 2012;9(9):e1001304.

6. DeSilva M, Merry S, Fischer P, Rohrer J, Isichei C, Cha S. Youth, unemployment and male gender predict mortality in AIDS patients started on HAART in Nigeria. AIDS Care 2009;21(1):70-77.

7. Druyts E, Dybul M, Kanters S, et al. Male gender and the risk of mortality among individuals enrolled in antiretroviral treatment programs in Africa: A systematic review and meta-analysis. AIDS 2012 (in press). [http://dx.doi.org/10.1097/ QAD.0b013e328359b89b]

8. Hawkins C, Chalamilla G, Okuma J, et al. Sex differences in antiretroviral treatment outcomes among HIV-infected adults in an urban Tanzanian setting. AIDS 2011;25(9):1189-1197. [http://dx.doi.org/10.1097/QAD.0b013e3283471deb]

9. Dorrington R, Bourne D, Bradshaw D, Laubscher R, Timaeus I. The Impact of HIV/AIDS on Adult Mortality in South Africa. Cape Town: Medical Research Council, 2001.

10. World Health Organization. Why Gender and Health? http://www.who.int/gender/ genderandhealth/en/index.html (accessed 1 August 2012).

11. Republic of South Africa. Constitution of the Republic of South Africa, 1996

12. Freedman L, Waldman R, de Pinho H, Wirth M, Chowdhury A, Rosenfield A. Who's Got The Power: Transforming Health Systems for Women and Children. New York: United Nations Development Programme, 2005.

13. Govender V, Penn-Kekana L. Gender Biases and Discrimination: A Review of Health Care Interpersonal Interactions. Background paper prepared for the Women and Gender Equity Knowledge Network of the WHO Commission on Social Determinants of Health. Cape Town: Health Economics Unit, School of Public Health and Family Medicine, University of Cape Town, and Centre for Health Policy, School of Public Health, University of Witwatersrand, 2007.

14. Harris B, Goudge J, Ataguba J, et al. Inequities in access to health care in South Africa. J Public Health Policy 2011;32:S102-S123. [http://dx.doi.org/10.1057/jphp.2011.35]

15. Krieger N, Chen J, Selby J. Class inequalities in women's health: Combined impact of childhood and adult social class - a study of 630 US women. Public Health 2001;11(3):175-185. [http://dx.doi.org/10.1038/sj/ph/1900754]

16. Moser K, Pugh H, Goldblatt P. Inequalities in women's health: Looking at mortality differentials using an alternative approach. BMJ (Clin Res Ed) 1988;296(6631):1221-1224

17. Moss N. Gender equity and socioeconomic inequality: A framework for the patterning of women's health. Soc Sci Med 2002;54(5):649-661.

18. Namasivayam A, Osuorah D, Syed R, Antai D. The role of gender inequities in women's access to reproductive health care: A population-level study of Namibia, Kenya, Nepal, and India International Journal of Women's Health 2012;4(1):351364. [http://dx.doi.org/10.2147/IJWH.S32569]

19. Reed A. Women's healthcare disparities and discrimination. Civil Rights Journal 1999;4(1):42.

20. Ro A, Choi K-H. Effects of gender discrimination and reported stress on drug use among racially/ethnically diverse women in Northern California. Women's Health Issues 2010;20(3):211-218.

21. Zierler S, Krieger N. Reframing women's risk: Social inequalities and HIV infection. Annu Rev Public Health 1997;18:401-436. [http://dx.doi.org/ 10.1146/ annurev.publhealth.18.1.401]

22. United States of America. National Institutes of Health Guidelines on the Inclusion of Women and Minorities as Subjects in Clinical Research. http://grants.nih.gov/ grants/guide/notice-files/not94-100.html (accessed 12 June 2012).

23. Stringer JSA, Zulu I, Levy J, et al. Rapid scale-up of antiretroviral therapy at primary care sites in Zambia. JAMA 2006;296(7):782-793. [http://dx.doi.org/10.1001/jama.296.7.782]

24. Cornell M, Technau K, Fairall L, et al. Monitoring the South African National Antiretroviral Treatment Programme, 2003 - 2007: The IeDEA Southern Africa collaboration. S Afr Med J 2009;99(9):653-660. 